\title{
Evaluation of a Dose-Monitoring Method for Prophylactic Anticoagulant Therapy with Low-Molecular-Weight Heparin
}

\author{
Shintaro Makino, Motoi Sugimura, Takashi Yorifuji, Taro Koshiishi, Toshitaka Tanaka, \\ Satoru Takeda
}

Department of Obstetrics and Gynecology, Juntendo University, Bunkyo-ku, Tokyo, Japan.

Email: shintaro@juntendo.ac.jp

Received April 15 $5^{\text {th }}, 2011$; revised July 20 ${ }^{\text {th }}, 2011$; accepted August 20 ${ }^{\text {th }}, 2011$.

\begin{abstract}
Objective: In the present study, we report on the results of our investigation of optimum dose monitoring using coagulation and fibrinolytic system indicators during obstetric prophylactic anticoagulant therapy with enoxaparin. Study Design: Of 103 cases of cesarean section performed at our hospital, 37 cases were selected for this study after obtaining their consent for blood collection. Variables of the coagulation and fibrinolytic systems [anti-factor Xa activity, endogenous thrombin potential (ETP), prothrombin time (PT) or international normalized ratio (INR), activated partial thromboplastin time (APTT) and D-dimer levels] were determined. Results: In the 5-day administration group, the anti-factor Xa activitywas $0.0 \mathrm{U} / \mathrm{ml}$ on the postoperative day 1, increased to $0.05 \mathrm{U} / \mathrm{ml} \pm 0.04 \mathrm{U} / \mathrm{ml}$ on the postoperative day 3, and mildly increased to $0.06 \mathrm{U} / \mathrm{ml} \pm 0.05 \mathrm{U} / \mathrm{ml}$ on the postoperative day 5. On the other hand, the anti-factor Xa activity in the 3-day administration group was $0.0 \mathrm{U} / \mathrm{ml}$ on the postoperative day 1 (before enoxaparin administration), increased to $0.06 \mathrm{U} / \mathrm{ml} \pm 0.05 \mathrm{U} / \mathrm{ml}$ on the postoperative day 3 , and significantly decreased to $0.02 \mathrm{U} / \mathrm{ml} \pm 0.03 \mathrm{U} / \mathrm{ml} \mathrm{on}$ the postoperative day $5(p=0.003)$; thus, the pattern of change was significantly different from that in the 5-day administration group $(p=0.004)$. Enoxaparin administration did not result in any significant fluctuation of the ETP, and no significant difference was observed between the 5-day and 3-day administration groups. Conclusion: Enoxaparin administration was associated with increase of the anti-factor Xa activity, and prolonged administration led to more sustained increase of the activity.
\end{abstract}

Keywords: Cesarean Section, Prophylactic Anticoagulant Therapy, Low-Molecular-Weight Heparin, Anti-Factor Xa Activity, Endogenous Thrombin Potential Introduction

\section{Introduction}

In recent years, deep venous thrombosis (DVT) and venous thromboembolism (VTE) have also attracted much attention in Japan, and it has become apparent that their incidence rates in Japan are not much lower than those in Europe or the United States. As a result, with the introduction of the Japanese Guideline for the Prevention of Venous Thromboembolism [1] and assignment of National Health Insurance points to the VTE prevention management fee, prophylactic anticoagulant therapy administered for cases of high-risk laparotomy is also covered by the National Health Insurance. Physical prophylaxis and anticoagulant therapy have been shown to be necessary for the prevention of VTE and a decrease in the mortality rate associated with this condition. Inevitably, such changes in the healthcare environment can be expected to lead to changes in the obstetric management of thromboembolism. Enoxaparin is a low-molecularweight heparin which blocks the activity of both FXa and thrombin (FIIa). Administration of enoxaparin, which has recently become available for clinical use in Japan, after cesarean sections is recommended by relevant guidelines in developed countries. Especially in the United Kingdom, prophylactic heparin therapy is administered to all pregnant women undergoing cesarean section [2]. In France, low-molecular-weight heparin is administered for 7 to 14 days as prophylaxis against VTE to women 
undergoing emergent cesarean section, and also to women with 3 or more risk factors who undergo planned cesarean section [3]. Although monitoring of enoxaparin effect has, until now, not been considered to be necessary, there have been a few reports of serious adverse reactions. For example, the estimated incidence of VTE after cesarean delivery and the haemorrhagic risk related to lowmolecular-weight heparin are reported to be $0.15 \%$ $0.22 \%$ and $0.23 \%-0.35 \%$, respectively [4]. While spinal subdural hematoma associated with epidural catheterizetion or accidental removal of catheter is rare, potentially serious complications can occur under administration of low-molecular-weight heparin [5]. Therefore, we consider it necessary to establish an appropriate clinical assessment and monitoring method for patients receiving low-molecular-weight heparin prophylaxis, to prevent these hemorrhagic complications. In the present study, we measured the anti-factor $\mathrm{Xa}$ activity, endogenous thrombin potential (ETP), prothrombin time-international normalized ratio (PT-INR), activated partial thromboplastin time (aPTT) and plasma D-dimer levels in order to investigate the optimum treatment monitoring method during obstetric prophylactic anticoagulant therapy with enoxaparin.

\section{Materials and Methods}

\subsection{Patients}

Of 103 cases of cesarean section (including emergent cesarean section) performed at Juntendo Hospital, Tokyo, Japan between October 2009 and January 2010, 37 cases without a past or family history of DVT or pulmonary thromboembolism were selected for this study. The indications for previous cesarean section include breech presentation, multiple pregnancy, placenta previa, non-reassuring fetal status, arrest of labor, and fetal anomaly. In every cesarean section, low-transverse incision and double layer closure of the uterine myometrium were performed. This study was conducted with written informed consent from the patients, obtained prior to the start of the study, and with the approval of the Juntendo University Ethics Committee.

\subsection{Study Treatment}

The template is used to format your paper and style the text. All margins, column widths, line spaces, and text fonts are prescribed; please do not alter them. You may note peculiarities. For example, the head margin in this template measures proportionately more than is customary. This measurement and others are deliberate, using specifications that anticipate your paper as one part of the entire proceedings, and not as an independent document.
Please do not revise any of the current designations.

\subsection{Blood Sample Collection}

On the postoperative day 1 (before the start of enoxaparin administration), the postoperative day 3 (10 hours after the last enoxaparin administration), and postoperative day 5 (10 hours after the last enoxaparin administration), $2 \mathrm{ml}$ blood specimens were collected in $0.125 \%$ sodium citrate at the same time of routine postoperative blood examination. After centrifugation at $1700 \times 15 \mathrm{~min}$, platelet free plasma was immediately separated and stored frozen at $-80^{\circ} \mathrm{C}$.

\subsection{Laboratory Analysis}

Variables of the coagulation and fibrinolytic systems [anti-factor Xa activity, endogenous thrombin potential (ETP), prothrombin time international normalized ratio (PT-INR), activated partial thromboplastin time (aPTT) and D-dimer levels] were determined. And, the correlation between each results and BMI, blood creatinine level, estimated glomelular filtration rate (eGFR) were also evaluated.

\subsubsection{Anti-Factor Xa Activity}

The instruments used for anti-factor Xa activity was the Amax 190+. The assay was performed in the presence of excess FXa and exogenous antithrombin (AT) to compensate for any deficiency of AT in the plasma. The AT-drug complex neutralizes a given quantity of FXa. A substrate specific for FXa was added and the residual FXa cleaves the substrate, resulting in release of paranitroaniline (pNA). The reaction was read at an optical density of $405 \mathrm{~nm}$ and is inversely proportional to the amount of enoxaparin present in the plasma. The plasma level of enoxaparin was determined by measuring its anti-factor Xa activity using a common calibration line established for this drug.

\subsubsection{Endogenous Thrombin Potential (ETP)}

In order to determine the ETP, $80 \mu \mathrm{l}$ of a sample warmed to $37^{\circ} \mathrm{C}$ was added to 98 -well round-bottom enzyme immunoassay plates. The sample was incubated at $37^{\circ} \mathrm{C}$ for 5 minutes with $0.5 \mathrm{pM}$ recombinant tissue factor and 24 $\mu \mathrm{M}$ phospholipid vesicles (PC/PS/PE). The sample was then mixed with $20 \mu \mathrm{l}$ fluorogenic substrate $(0.1 \mathrm{M}$ $\mathrm{CaCl} 2$ or $2.5 \mathrm{mM} \mathrm{Z-Gly-Gly-Arg-AMC)}$ and measured using a fluorogenic substrate assay (Ex: $390 \mathrm{~nm} / \mathrm{Em}: 460$ $\mathrm{nm}$; Thrombinoscope Co., Ltd.). The amount of thrombin generated in time $[\mathrm{nM}]$ was integrated to determine the ETP.

\subsection{Statistical Analysis}

Student's t-test was used for the statistical analysis, and 
the Pearson's correlation coefficient was calculated for the correlation analysis; $p$ values of less than 0.05 were considered to indicate statistical significance.

\section{Results}

\subsection{Patient Characteristics}

No significant differences were found between the 5-day administration group and the 3-day administration group in the mean maternal age, body mass index (BMI), mean history of delivery (times), mean gestational week of delivery, ratio of planned vs. emergent cesarean section, or the birth weight of the newborns (Table 1).

\subsection{Anti-Factor Xa Activity}

In the 5-day administration group, the anti-factor Xa activity (blood concentration of enoxaparin) was $0.0 \mathrm{U} / \mathrm{ml}$ on postoperative day 1 (before the 1st enoxaparin administration), increased to $0.05 \mathrm{U} / \mathrm{ml} \pm 0.04 \mathrm{U} / \mathrm{ml}$ by postoperative day 3 , and increased slightly further to 0.06 $\mathrm{U} / \mathrm{ml} \pm 0.05 \mathrm{U} / \mathrm{ml}$ by postoperative day 5 (Figure 1). On the other hand, the anti-factor Xa activity in the 3-day administration group was $0.0 \mathrm{U} / \mathrm{ml}$ on postoperative day 1 , increased to $0.06 \mathrm{U} / \mathrm{ml} \pm 0.05 \mathrm{U} / \mathrm{ml}$ by postoperative day 3 , and decreased significantly to $0.02 \pm 0.03 \mathrm{U} / \mathrm{ml}$ by postoperative day $5(\mathrm{p}=0.003)$ (Figure 2); thus, the pattern of changes of anti-factor Xa activity in this group was significantly different from that in the 5-day administration group $(p=0.004)$. The case marked with the arrow in Figure 2 is that of a patient who developed subfascial hematomas of the cesarean section wound during enoxaparin administration. The patient had undergone emergent cesarean section for severe preeclampsia. The newborn weighed $2714 \mathrm{~g}$, was male, and had an Apgar score of 9/10 and umbilical arterial blood $\mathrm{pH}$ of 7.251. Subfascial hematomas measuring $3.6 \mathrm{~cm} \times 2.0 \mathrm{~cm}$ around the abdominal wall wound and $2.7 \mathrm{~cm} \times 4.2 \mathrm{~cm}$ on the left upper side of the wound were confirmed on abdominal contrast-enhanced computed tomography (Figure 3). The anti-factor Xa activity on postoperative day 3 was high at $0.22 \mathrm{U} / \mathrm{ml}$, exceeding the mean by +1.5 standard deviation (SD). Thus, a diagnosis of hematoma associated with enoxaparin administration was made. Immediate decreases of the anti-factor Xa activity and sizes of the subfascial hematomas were noted after the discontinuation of enoxaparin administration.

\subsection{ETP}

Enoxaparin administration did not result in any signifycant fluctuation of the ETP, and no significant difference was observed between the 5-day and 3-day administration groups (Figures $\mathbf{4}$ and 5).
Table 1. Patient characteristics (mean \pm SD).

\begin{tabular}{cccc}
\hline & $\begin{array}{c}\text { 5-day administration } \\
\text { group }\end{array}$ & $\begin{array}{c}\text { 3-day administration } \\
\text { group }\end{array}$ & $\mathrm{p}$ value \\
\hline Age (years) & $36.1 \pm 6.3$ & $35.5 \pm 3.5$ & $\mathrm{p}=0.62$ \\
BMI (kg) & $23.6 \pm 2.9$ & $23.2 \pm 4.0$ & $\mathrm{p}=0.89$ \\
$\begin{array}{c}\text { History of } \\
\text { delivery (times) }\end{array}$ & $0.3 \pm 0.6$ & $0.4 \pm 0.8$ & $\mathrm{p}=0.86$ \\
$\begin{array}{c}\text { Gestational } \\
\text { weeks of delivery } \\
\text { (weeks) }\end{array}$ & $36.1 \pm 6.3$ & $36.5 \pm 3.4$ & $\mathrm{p}=0.58$ \\
$\begin{array}{c}\text { planned vs. } \\
\text { emergent cesarean } \\
\text { section (\%) }\end{array}$ & $5 / 20(25 \%)$ & $4 / 17(23.5 \%)$ & $\mathrm{p}=0.80$ \\
$\begin{array}{c}\text { birth weight of } \\
\text { the newborns (g) }\end{array}$ & $2725.1 \pm 875.6$ & $2606.5 \pm 655.4$ & $\mathrm{p}=0.87$ \\
\hline
\end{tabular}

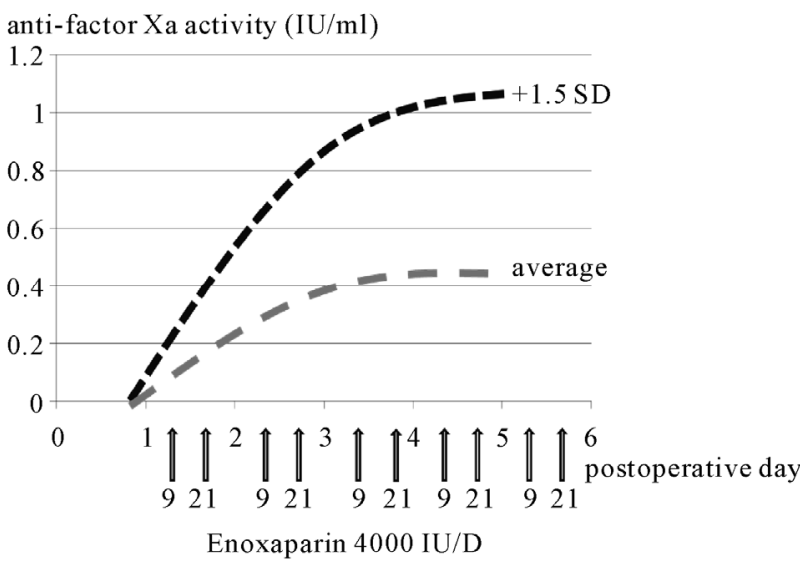

Figure 1. Anti-factor $\mathrm{Xa}$ activity (five-day administration group). Blue line shows average and red line shows +1.5 SD.

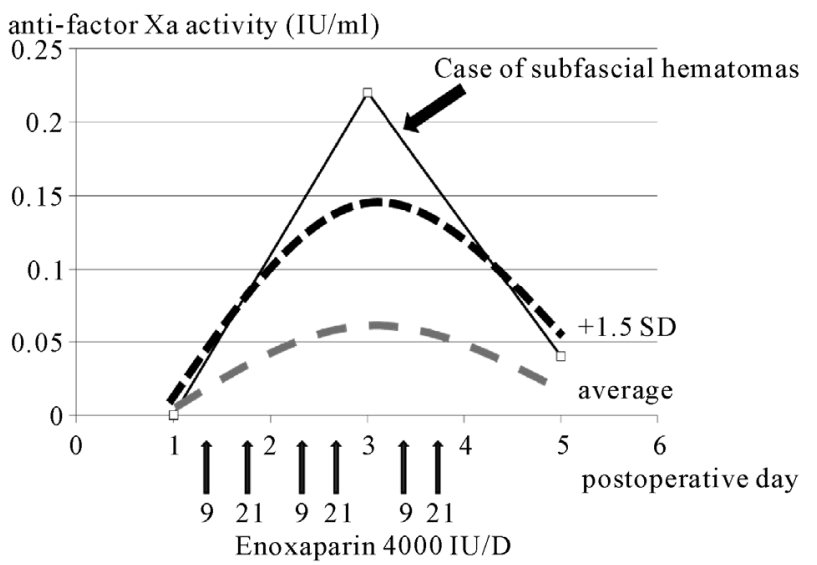

Figure 2. Anti-factor Xa activity (three-day administration group). Blue line shows average and red line shows +1.5 SD. The case marked with arrow in Figure 3 was a case of subfascial hematomas of the cesarean section wound during enoxaparin administration. 


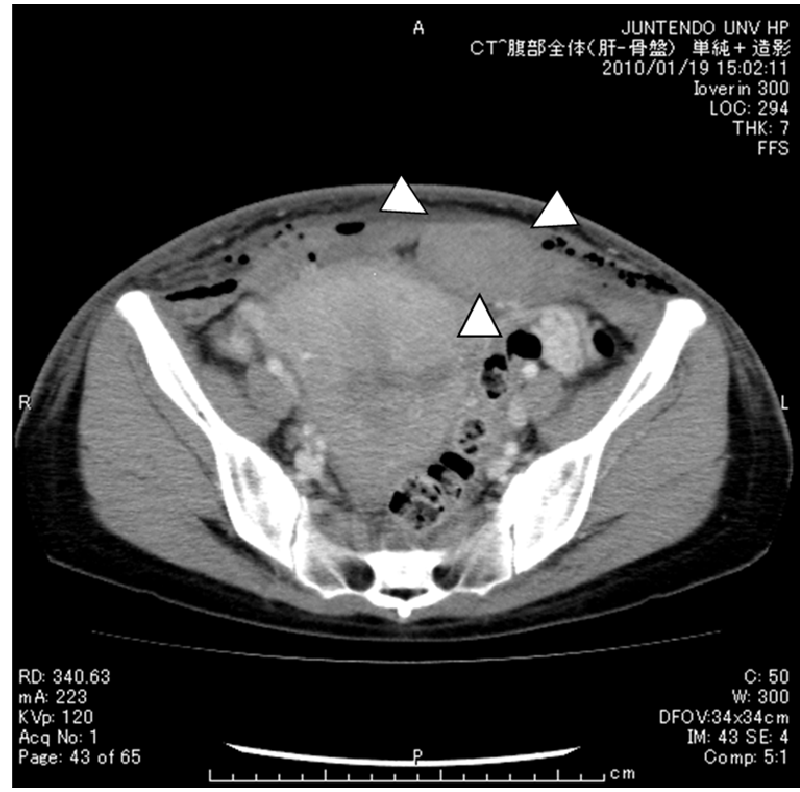

(a)

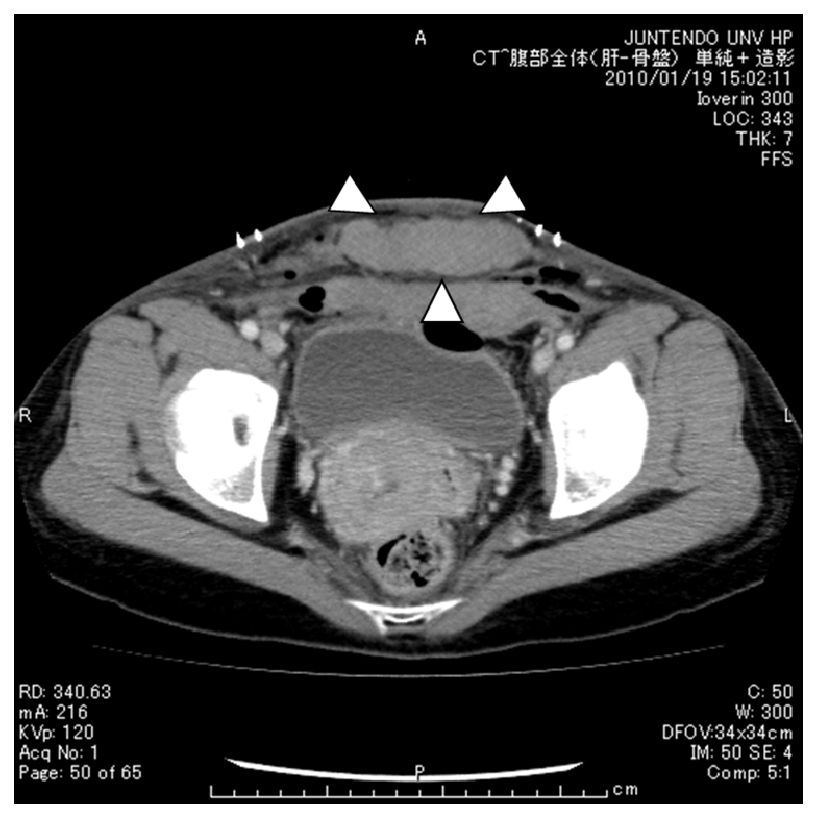

(b)

Figure 3. Abdominal enhanced CT (a) Subfascial hematoma $(3.6 \times 2.0 \mathrm{~cm})$; (b) Abdominal wall wound $(2.7 \times 4.2 \mathrm{~cm})$.

\subsection{PT-INR, APTT, D-Dimer}

No significant fluctuations were found in the PT-INR, APTT or D-dimer levels postoperatively in either group. Moreover, the anti-factor Xa activity and ETP were weakly, but not significantly, correlated with the PT-INR, APTT or plasma D-dimer levels. No significant correlations of the anti-factor Xa activity or ETP with the BMI,

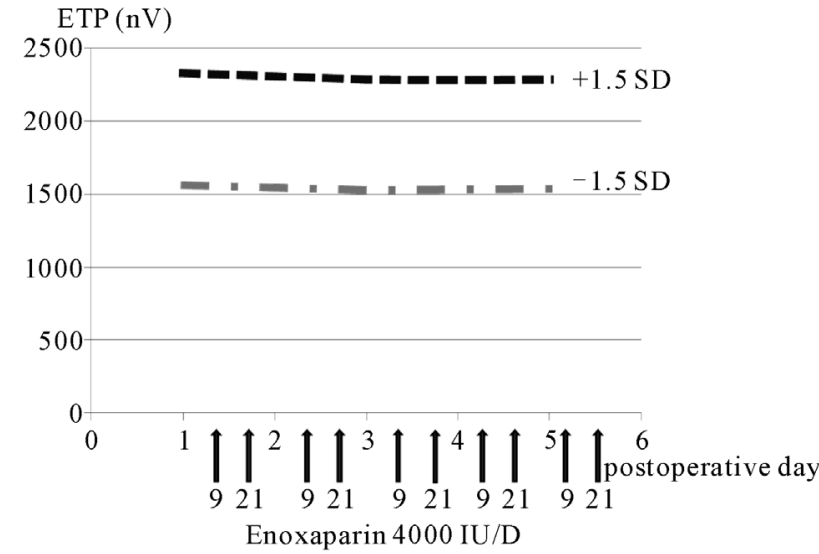

Figure 4. ETP (five-day administration group).

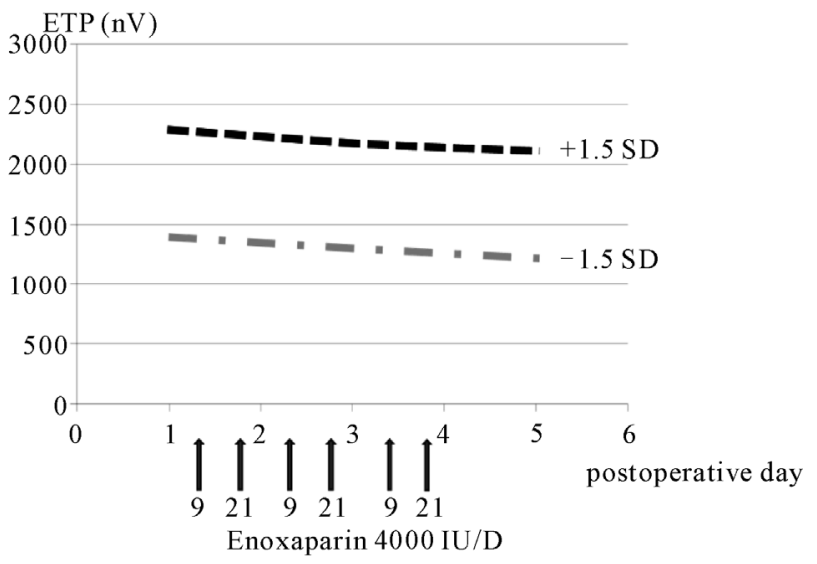

Figure 5. ETP (three-day administration group).

serum creatinine level or eGFR were noted.

\section{Discussion}

In this study, we conducted serial measurements of the anti-factor Xa activity, PT-INR, APTT and plasma D-dimer levels during anticoagulant therapy with enoxaparin in women who undergoing cesarean section. Enoxaparin administration was associated with an increase of the anti-factor Xa activity, and more prolonged administration led to more sustained increase of the activity. Although no significant fluctuation was found in the ETP, the blood collection at 10 hours after enoxaparin administration in this study appeared to be inadequate to evaluate the effect on thrombin generation. Enoxaparin, a LMWH produced by chemical depolymerization of UFH, acts by anti-thrombin (AT)-dependent inhibition of F Xa. Some of the LMWH molecules have been reported to have sufficient chain length to bridge AT to thrombin, thereby exerting an anti-IIa effect [6]. There have been few randomized trials on the use of LMWH either antenatally or postoperatively as proposed [7]. A variety of 
randomized control trials have assessed the efficacy of LMWH as compared with that of standard heparin in reducing the risk of thromboembolic disease following major abdominal surgery, and the two appear to be comparable in terms of their therapeutic efficacy $[8,9]$. In one randomized controlled trial which specifically assessed the occurrence of complications following the use of either type of heparin, a clear advantage of LMWH was found in a sub-group analysis: reduction of the need for re-operation (RR $0.55,95 \%$ CI $0.31-0.98$ ) and only minor bleeding episodes (RR 0.78. 95\%CI 0.29 - 0.89) [10]. In women receiving LWMH during pregnancy, the plasma anti-factor Xa activity has been shown to be significantly correlated with the minimal weight-based dose. However, no such correlation was found with the maternal age, weight, body mass index, or gestational age [11]. In one report in the literature of a comparison of the plasma anti-factor Xa activity and reduction in the plasma concentration of the thrombin-antithrombin (TAT) complex in patients receiving dalteparin 5000 IU once daily, enoxaparin $4000 \mathrm{IU}$ once daily, or tinzaparin $50 \mathrm{IU} / \mathrm{kg}$ once daily following cesarean section [12], no significant differences in the mean anti-factor Xa activity $(\mathrm{p}<0.005)$ or reduction of the plasma TAT concentration $(\mathrm{p}<0.005)$ was found among the three LWMH groups in blood samples obtained at 0, 1, 3, 6, 12 and 24 hours after the dosing. Because no significant correlations of the anti-factor $\mathrm{Xa}$ activity with the PT-INR, APTT and plasma D-dimer levels, or with the BMI, serum creatinine, eGFR and postoperative hourly urine output, it was difficult to estimate the activity indirectly. Thus, it is suggested that measurement of the plasma anti-factor Xa activity may be useful as an important indicator of the optimum dose in patients whose renal function is predicted to worsen before or after the operation due to pregnancy-induced hypertension. Moreover, because some cases in the 5-day administration group showed elevation of the anti-factor $\mathrm{Xa}$ activity, the accumulation potential of enoxaparin also needs to be considered. Our study had several potential limitations. First, we studied only a small number of patients undergoing cesarean section. Second, the blood samples were obtained only at 10 hours after the administration of $2000 \mathrm{IU}$ of enoxaparin. Because this was a pilot study, blood samples were obtained at the same time as routine postoperative blood samplings. However, this is the first investigation measuring the anti-factor $\mathrm{Xa}$ activity after enoxaparin administration in Japanese women undergoing cesarean section. The mean anti-factor Xa activity measured by us was extremely close to the 10-hour value after administration of $2000 \mathrm{U}$ of enoxaparin to a healthy adult male $(0.05 \mathrm{IU} / \mathrm{ml})$. It was considered that investigation of temporal fluctuations of the anti-factor Xa activity after enoxaparin administration during pregnancy and after delivery is necessary for establishment of the optimum dose under coagulation monitoring in Japan. The patient who developed subfascial hematomas of the cesarean section wound had been diagnosed as having severe preeclampsia, with mild decrease of the eGFR which did not necessitate reduction in the dose or discontinuation of enoxaparin administration. However, based on the postoperative course of changes in the anti-factor Xa activity, it is highly likely that delayed enoxaparin metabolism due to temporary worsening of the renal function after the operation increased the blood concentration of the drug, leading to the formation of the wound hematomas. Thus, dose adjustments may be necessary in cases in which elevation of the anti-factor $\mathrm{Xa}$ activity exceeds the mean by over $+1.5 \mathrm{SD}$. In conclusion, we observed that significant variances of the anti-factor Xa activity existed among patients treated with low-molecular heparin postoperatively as prophylaxis against VTE. This observation may suggest that monitoring for anti-factor Xa activity is important to prevent serious or major bleeding after surgery. Thus, investigation of the suitable indications, duration, and optimum dose of prophylactic anticoagulant therapy in the future might be important in Japan. Especially, in order to avoid the risk of suitable indications as far as possible, selection of suitable postoperative analgesic treatment so as to avoid spinal hematoma associated epidural anesthesia or irreversible anesthesia may also be important.

\section{REFERENCES}

[1] Editorial Committee on Japanese Guideline for Prevention of Venous Thromboembolism, "Japanese Guideline for Prevention of Venous Thromboembolism, Guideline 1-19," Medical Frontier International Limited, Tokyo, 2006.

[2] Agency for Health and Quality, "Reducing the Risk of Thromboembolism during Pregnancy, Birth and the Puerperium," Royal College of Obstetricians and Gynaecologists, London, Green-Top Guideline No. 37, 2009.

[3] C. M. Samama, "Venous Thromboembolism Prevention in Surgery and Obstetrics: Clinical Guidelines," European Journal of Anaesthesiology, Vol. 23, No. 2, 2006, pp. 95-116.

[4] M. Blondon, A. Perrier, M. Nendaz, M. Righini, F. Boehlen, M. Boulvain and P. De Moerloose, "Thromboprophylaxis with Low-Molecular-Weight Heparin after Cesarean Delivery," Journal of Thrombosis and Haemostasis, Vol. 103, No. 1, 2009, pp. 129-137. doi:10.1160/TH09-06-0349

[5] E. Forsnes, A. Occhino and R. Acosta, "Spontaneous Spinal Epidural Hematoma in Pregnancy Associated with Using Low Molecular Weight Heparin," Obstetrics \& 
Gynecology, Vol. 113, No. 2, 2009, pp. 532-533.

[6] J. I. Weitz, J. Hirsh and M. M. Samansa, "New Anticoagulant Drugs," Chest, Vol. 126, No. S3, 2004, pp. 265286. doi:10.1378/chest.126.3_suppl.265S

[7] F. B. Robert, T. G. Eng, S. G. Alexander, M. W. Euan and A. B. Elizabeth, "A Randomized Double-Blind Placebo Controlled Trial of Low Molecular Weight Heparin as Prophylaxis in Preventing Venous Thrombolic Events after Cesarean Section: A Pilot Study," British Journal of Obstetrics and Gynaecology, Vol. 108, No. 8, 2001, pp. 835-839.

[8] European Fraxiparin Study Group, "Comparison of a Low Molecular Weight and Unfractionated Heparin for the Prevention of Deep Vein Thrombosis in Patients Undergoing Abdominal Surgery," British Journal of Surgery, Vol. 75, No. 11, 1988, p. 1058. doi:10.1002/bjs. 1800751105

[9] M. Koller, U. Schoch, P. Buchmann, F. Largiader, A. von Falten and P. G. Frick, "Low Molecular Weight Heparin (Kabi 2165) as Thromboprophylaxis in Electine Visceral Surgery: A Randomized, Bouble-Blind Study versus Un- fractionated Heparin," Journal of Thrombosis and Haemostasis, Vol. 56, 1986, p. 243.

[10] V. V. Kakkar, A. T. Cohen, R. A. Edmonson, M. J. Phillips, D. J. Cooper, S. K. Das, K. T. Maher, R. M. Sanderson, V. P. Ward and S. Kakkar, "Low Molecular Weight versus Standard Heparin for Prevention of venous Thromboembolism after Major Abdominal Surgery," Lancet, Vol. 34, No. S4, 1993, pp. 259-265.

[11] N. S. Fox, S. K. Laughon, S. D. Bender, D. H. Saltzman and A. Rebarber, "Anti-Factor Xa Plasma Levels in Pregnant Women Receiving Low Molecular Weight Heparin Thromboprophylaxis," Obstetrics \& Gynecology, Vol. 112, No. 4, 2008, pp. 884-889. doi:10.1097/AOG.0b013e31818638dc

[12] J. Ellison, A. J. Thompson, J. A. Conkie, F. McCall, D. Walker and A. Greer, "Thromboprophylaxis Following Cesarean Section-A Comparison of the Antithrombolic Properties of Three Low Molecular Weight Heparins-Dalteparin, Enozaparin and Tinzaparin," Journal of Thrombosis and Haemostasis, Vol. 86, No. 6, 2001, pp. 1374-1378. 